Social relations and presence of others predict bystander intervention Evidence from violent incidents captured on CCTV

Liebst, Lasse Suonpera; Philpot, Richard; Bernasco, Wim; Dausel, Kasper Lykke; EjbyeErnst, Peter; Nicolaisen, Mathias Holst; Lindegaard, Marie Rosenkrantz

Published in:

Aggressive Behavior

DOI:

10.1002/ab.21853

Publication date:

2019

Document version

Publisher's PDF, also known as Version of record

Document license:

CC BY-NC

Citation for published version (APA):

Liebst, L. S., Philpot, R., Bernasco, W., Dausel, K. L., Ejbye-Ernst, P., Nicolaisen, M. H., \& Lindegaard, M. R. (2019). Social relations and presence of others predict bystander intervention: Evidence from violent incidents captured on CCTV. Aggressive Behavior, 45(6), 598-609. https://doi.org/10.1002/ab.21853 


\title{
Social relations and presence of others predict bystander intervention: Evidence from violent incidents captured on CCTV
}

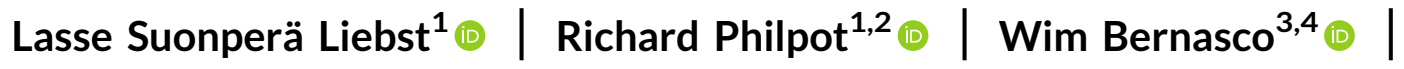

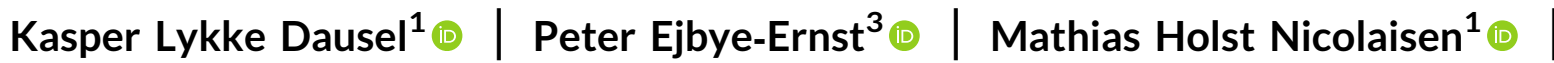 \\ Marie Rosenkrantz Lindegaard ${ }^{1,3}$
}

${ }^{1}$ Department of Sociology, University of Copenhagen, Copenhagen, Denmark

${ }^{2}$ Department of Psychology, Fylde College, Lancaster University, Lancaster, United Kingdom

${ }^{3}$ Netherlands Institute for the Study of Crime and Law Enforcement (NSCR), Amsterdam,

The Netherlands

${ }^{4}$ Department of Spatial Economics, School of Business and Economics, Vrije Universiteit Amsterdam, Amsterdam, The Netherlands

\section{Correspondence}

Wim Bernasco, Department of Spatial

Economics, School of Business and Economics, Vrije Universiteit Amsterdam, De Boelelaan 1105, 1081 HV Amsterdam, The Netherlands.

Email; wbernasco@nscr.nl

Funding information

Velux Fonden; Det Frie Forskningsråd, Grant/ Award Number: DFF - 6109-00210

\begin{abstract}
Are individuals willing to intervene in public violence? Half a century of research on the "bystander effect" suggests that the more bystanders present at an emergency, the less likely each of them is to provide help. However, recent meta-analytical evidence questions whether this effect generalizes to violent emergencies. Besides the number of bystanders present, an alternative line of research suggests that preexisting social relations between bystanders and conflict participants are important for explaining whether bystanders provide help. The current paper offers a rare comparison of both factors-social relations and the number of bystanders presentas predictors of bystander intervention in real-life violent emergencies. We systematically observed the behavior of 764 bystanders across 81 violent incidents recorded by surveillance cameras in Copenhagen, Denmark. Bystanders were sampled with a case-control design, their behavior was observed and coded, and the probability of intervention was estimated with multilevel regression analyses. The results confirm our predicted association between social relations and intervention. However, rather than the expected reversed bystander effect, we found a classical bystander effect, as bystanders were less likely to intervene with increasing bystander presence. The effect of social relations on intervention was larger in magnitude than the effect of the number of bystanders. We assess these findings in light of recent discussions about the influence of group size and social relations in human helping. Further, we discuss the utility of video data for the assessment of real-life bystander behavior.
\end{abstract}

KEYWORDS

bystander effect, intervention, social groups, video observation, violence 


\section{1 | INTRODUCTION}

In the presence of others, bystanders are less likely to intervene when they witness someone in need of help (Darley \& Latané, 1968). This bystander effect is one of the most well-established findings of psychology (Manning, Levine, \& Collins, 2007), and is typically interpreted as the product of a diffusion of responsibility, by which the liability to help dilutes across the multiple bystanders present (Latané \& Nida, 1981). Paradoxically, although the bystander research field was prompted by the violent 1964-murder of Kitty Genovese, and the inaction of the witnesses present (but see Manning et al., 2007), experimental research has rarely examined bystander behavior in the context of violent attacks (Cherry, 1995; Liebst, Heinskou, \& Ejbye-Ernst, 2018). This omission is a result of the practical and ethical infeasibility of exposing participants to objectively or subjectively dangerous study conditions (Osswald, Greitemeyer, Fischer, \& Frey, 2010).

By restricting the analysis of bystander behavior to laboratory settings-in which neither the victims nor the bystanders are exposed to danger-the field risks isolating itself away from the phenomenon it initially set out to explain (Mortensen \& Cialdini, 2010). Confirming this concern, in the exceptionally few experimental studies that have simulated attacks, it is found that bystanders are equally (Fischer, Greitemeyer, Pollozek, \& Frey, 2006), or more (Harari, Harari, \& White, 1985) likely to intervene in the presence of others than when alone. Further, a meta-analysis of the experimental literature concludes that the bystander effect attenuates, or even reverses, in high-danger study contexts where the victims, the bystanders, or both are exposed to dangerous situations (Fischer et al., 2011).

Taken together, when uncoupling the experimental evidence into the trivial (e.g., a pencil spill, a door that needs to be answered) and the more dangerous emergencies, the classical bystander effect does not seem to generalize across both domains. Rather, in study contexts where intervention may be dangerous for participants, the presence of additional bystanders may provide welcome physical support that promotes intervention (Fischer \& Greitemeyer, 2013). In line with this interpretation, observational evidence from real-life emergencies captured by surveillance cameras shows a positive relationship between group size and the number of interventions (Levine, Taylor, \& Best, 2011). Further, a cross-national video analysis finds that at least one bystander intervenes in 9 out of 10 public space conflicts, with the likelihood of victim help increasing with greater bystander presence (Philpot, Liebst, Levine, Bernasco, \& Lindegaard, 2019). The overall finding that individuals do intervene when it really matters aligns with cross-cultural anthropological accounts suggesting that third-party intervention in everyday conflicts is most likely a human universal (Boehm, 2000; Brown, 1991; Eibl-Eibesfeldt, 1989; Fry, 2000).

Shifting away from a situational emphasis on how additional individuals promote nonintervention, or the potential reversal of such effect, an alternative line of research stresses the importance of social relations in bystander helping (Levine \& Manning, 2013; Philpot, 2017;
Swann \& Jetten, 2017). Specifically, those bystanders who are affiliated with a person in an emergency situation are significantly more likely to intervene than those who are socially distant. This association is found not only across experimental and observational studies with humans (Levine, Cassidy, Brazier, \& Reicher, 2002; Lindegaard et al., 2017; Slater et al., 2013) but also in nonhuman primates (de Waal, 2015). These findings are consistent with an evolutionary theory of cooperation that expects helping behavior to occur disproportionately between genetically related or reciprocating individuals (de Waal \& Preston, 2017; Axelrod \& Hamilton, 1981; Vázquez, Gómez, Ordoñana, Swann, \& Whitehouse, 2017).

Besides de-escalatory helping, which exists as the main focus of bystander research (Fischer et al., 2011), group membership is also associated with escalatory interventions by which third-parties fight on behalf of their fellow group members (Black, 1993; Levine, Lowe, Best, \& Heim, 2012; Phillips \& Cooney, 2005; Swann, Gómez, Huici, Morales, \& Hixon, 2010). Social relations between bystanders and conflict participants thus seem to foster not only de-escalatory but also escalatory interventions.

Despite the coexistence of these partially competing accounts, few attempts have examined the relative contributions of the number of bystanders and social relations in explaining bystander intervention. This may result from the methodological circumstance that "laboratory studies of bystander intervention usually use strangers as research confederates who help to stage the helping dilemma" (Banyard, 2015, p. 30). Fischer et al. (2011) included bystander-victim familiarity as a moderator in their meta-analysis and found that the magnitude of the bystander effect was not influenced by whether or not the bystander knew the victim. Similarly, a regression analysis of in-depth interviews reports a significant bystander effect in a model in which social relations are the main predictor of bystander intervention (Phillips \& Cooney, 2005). By contrast, an examination of real-life bystander intervention in the aftermath of commercial robberies (Lindegaard et al., 2017) reports a weak reversed bystander effect in a model where social relations between victims and bystanders, again, dominates the intervention outcome. While these studies assess the net effects of these two factors, Levine and Crowther (2008) analyze the interaction between group size and social group identification and find that this inter-relationship could both increase or decrease the likelihood of bystander intervention.

These few studies examining the two factors simultaneously indicate that social relations outperform the number of bystanders as a predictor of intervention, while the evidence regarding the positive, vis-à-vis the negative, direction of the bystander effect remains mixed. However, these studies tend to rely on ecologically limited experimental paradigms and retrospective accounts (Baumeister, Vohs, \& Funder, 2007; Swann \& Jetten, 2017). An exception is the work of Lindegaard et al. (2017), which used video-based naturalistic observations of bystanders in the aftermath of nonfatal commercial robberies. However, by analyzing the period after the offenders had already left the setting, their study provides limited information on whether bystanders intervene in violent emergencies where intervention may be 
dangerous-that is, the condition proposed to attenuate or reverse the bystander effect. Overall, there is a dearth of direct comparisons of number of bystanders and social relations as predictors of bystander intervention in violent emergencies. The present study, which utilizes video recordings of public violent assaults, is the first systematic observational study to address this gap.

Given the dangerous nature of the violent situations under study, both for the antagonists and for potential interveners, we predicted a reversed bystander effect, with a positive association between the number of bystanders and the likelihood of bystander intervention (Hypothesis 1). We further predicted that bystanders who have a social relation with a conflict party are more likely to intervene than strangers (Hypothesis 2). As the evidence supporting the reversed bystander effect is less uniform than the evidence in favor of social relations, we expected that the effect of social relations on intervention will be larger in magnitude than the effect of the number of bystanders (Hypothesis

3). These hypotheses align with the majority of bystander research that considers intervention as unambiguously prosocial (i.e., helping behavior), and should therefore apply to de-escalatory interventions. Whether these propositions also fit escalatory interventions, where bystanders become conflict participants, is an open question that we also explore in the empirical analysis.

We control for other factors that may be related to the intervention likelihood, including the bystander's gender (Cross, Copping, \& Campbell, 2011; Eagly, 2009), whether the bystander is a member of the public or is serving an occupational role (e.g., bouncer, Hobbs, 2003), whether the event takes place in a nighttime drinking setting (Levine et al., 2012; Reynald, 2011), and two additional measures that may affect the bystander's intervention opportunity: the density of the situation (Macintyre \& Homel, 1997), and the spatial proximity of the bystander to the conflict participants (Macintyre \& Homel, 1997).

\section{DATA AND METHODS}

\section{1 | Data}

The data consists of 81 surveillance camera recordings of policereported public violent assaults in central Copenhagen between 2010 and 2012 (replication data and a Stata script are available as Supporting Information at osf.io/r25wu). ${ }^{1}$ The clips were a subset of a wider sample $(N=164),{ }^{2}$ and were selected if they conformed to the following three criteria. Each clip captured an event of physical violence, with or without intervening bystanders. The clip had a quality (e.g., brightness and resolution) that rendered it possible to conduct a systematic behavioral coding. Each clip captured the duration of the situation with none, or only negligible, breaks in the coverage (see Nassauer \& Legewie, 2012).

\section{2 | Coding procedure}

The coding began by identifying the conflicting parties, in most cases, the two individuals between whom the situation initially manifested itself as a conflict. This encounter was identified from displays of direct physical violence or from nonverbal cues of anger and aggression (e.g., emphasizing gestures, forward body inclination, see Dael, Mortillaro, \& Scherer, 2012). All individuals entering the ongoing conflict were defined as intervening bystanders.

With the use of a detailed observation codebook, four trained student assistants coded the bystander intervention behavior (Table A1 in the Appendix) and situational properties (Table A2 in the Appendix) of each clip. This codebook was compiled from existing variable definitions in the literature (e.g., "de-escalatory" and "escalatory" intervention types, see Levine et al., 2011) and specified through in-depth qualitative observations of a subsample of videos (see Eibl-Eibesfeldt, 1989; Jones et al., 2016).

In addition to the visual information obtained from the video recordings, each clip was also coupled with a police case file that provided descriptive accounts of the event. Pre-existing social relationships were by default inferred from nonverbal social behavioral cues observed in the footage (see Murphy, 2016). These cues included interactional displays of collective behavior-in-concert, such as moving in synchrony, shared focus and attention, and bodily proximity (Afifi \& Johnson, 2005; Ge, Collins, \& Ruback, 2012; Goffman, 1971). In ambiguous cases, coders validated these videobased group assessments against the police case file descriptions.

\section{3 | Interrater reliability}

To test the reliability of the variables included in the final analysis, we selected 20 (29\%) of the video contexts and 35 (15\%) of the intervening bystanders for double coding. All variables included in the analyses reached a Krippendorff's $\alpha$ value of $\geq 0.80$, recommended by Krippendorff (2004) as the cutoff point for reliable interrater agreement (for the Krippendorff values of all coded variables see Tables A1 and A2 in the Appendix). Disagreements between the coders were resolved through discussion Before analysis.

\section{4 | Case-control sampling}

Because the incidents involved many more nonintervening than intervening bystanders and because the behavioral coding is very timeconsuming, we applied a case-control approach (Keogh \& Cox, 2014). Here, we randomly selected a sample of nonintervening "controls," who were situated in the same time and place as the intervening "cases," but without displaying the intervention outcome of interest (Grimes \& Schulz, 2005). For sufficient statistical power, it is recommended to sample at least two, but no more than four, controls per case (Lewallen \& Courtright, 1998). With 510 nonintervening bystanders and 215 intervening bystanders included in the study, our control-to-case ratio is $2.4: 1$ and thus within these recommended thresholds.

\section{5 | Estimation}

To account for the hierarchical structure of our data, with bystanders nested into video contexts, data was estimated with two-level 
regression models with a random intercept (Hox, Moerbeek, \& van de Schoot, 2017). All estimations were calculated with Stata 14 's "gllamm" module using the adaptive quadrature estimation technique (Rabe-Hesketh, Skrondal, \& Pickles, 2005). The data showed an average of nine individuals nested across the 81 contexts, offering a sufficient sample size to obtain unbiased fixed-effect point estimates for most multilevel model specifications (McNeish \& Stapleton, 2016).

\section{6 | Sampling weights}

To make the randomly selected controls representative of the actual number of nonintervening bystanders in each context, data was modeled using sampling weights (Lohr, 2010). All interveners were assigned a weight of 1 . Controls were assigned a weight equal to the total number of noninterveners per context divided by the number of selected controls. In the relatively few contexts where the number of selected controls exceeded the number of noninterveners, the controls were assigned a weight of 1 . Before analysis, the weights were scaled to suit multilevel modeling (Carle, 2009).

\section{7 | Robustness tests}

In addition to confirmatory tests of the three hypotheses and an exploratory comparison between escalatory and de-escalatory intervention, we conducted sensitivity analyses to assess the robustness of our results against other reasonable data and model specifications (Steegen, Tuerlinckx, Gelman, \& Vanpaemel, 2016). These analyses included estimating combinations of independent variables using two alternative sampling weight scalings (Carle, 2009), and also the inclusion of the number of bystanders as a quadratic term, given that earlier research suggests that the negative association between number of bystanders and intervention diminishes curvilinearly with increasing numbers (Latané, 1981).

\section{8 | Measures}

\subsection{1 | Dependent variables}

We defined bystander intervention as a binary variable, distinguishing bystanders who intervene into the conflict (with either escalatory or de-escalatory acts) from bystanders that do not intervene. Decomposed bystander intervention was measured as a multinomial variable, distinguishing four possible bystanders based on their actions: nonintervention, only de-escalatory acts, only escalatory acts, and a mix of de-escalatory and escalatory acts. De-escalatory acts included making open-handed gestures, nonforceful touching, blocking contact between parties, holding a person back, hauling, and pushing the antagonists apart. Escalatory acts included pointing and threatening gestures, throwing a person, pushing, shoving, hitting, kicking, violence against a person on the ground, and weapon use (see Table A1 in the Appendix). Table 1 presents descriptive statistics of the dependent, independent, and control variables measured at the individual level. At the context-level, at least one bystander
TABLE 1 Descriptive statistics of unweighted variables

\begin{tabular}{|c|c|c|c|c|c|}
\hline Variable & $M$ & $S D$ & Min & Max & $N$ \\
\hline Bystander intervention & 0.29 & 0.45 & 0 & 1 & 747 \\
\hline \multicolumn{6}{|l|}{$\begin{array}{l}\text { Decomposed bystander } \\
\text { intervention }\end{array}$} \\
\hline De-escalatory & 0.20 & 0.40 & 0 & 1 & 747 \\
\hline Escalatory & 0.05 & 0.21 & 0 & 1 & 747 \\
\hline Mixed & 0.04 & 0.20 & 0 & 1 & 747 \\
\hline $\begin{array}{l}\text { Number of bystanders } \\
\text { (unstandardized) }\end{array}$ & 18.28 & 13.73 & 1 & 76 & 747 \\
\hline $\begin{array}{l}\text { Number of bystanders } \\
\text { (rescaled) }^{\mathrm{a}}\end{array}$ & 0.16 & 0.52 & -0.50 & 2.36 & 747 \\
\hline Social relation & 0.29 & 0.45 & 0 & 1 & 747 \\
\hline Male & 0.69 & 0.46 & 0 & 1 & 747 \\
\hline Nighttime drinking setting & 0.71 & 0.45 & 0 & 1 & 747 \\
\hline Bystander at work & 0.11 & 0.32 & 0 & 1 & 747 \\
\hline Spatial proximity & 0.44 & 0.50 & 0 & 0 & 741 \\
\hline People density & 0.38 & 0.49 & 0 & 1 & 747 \\
\hline
\end{tabular}

${ }^{a}$ Rescaled as $x^{\prime}=x-\mu x / 2 \sigma x$, that is, subtract the mean and divide by twice the standard deviation (see Gelman, 2008).

intervened in $85.0 \%$ of the 81 videos. In total, there were 217 intervening bystanders, with an average of 2.7 interveners per situation.

\subsection{2 | Independent variables}

The number of bystanders was a count of the individuals present in the emergency. This context-level predictor was standardized by subtracting the mean and dividing by two standard deviations as to make it comparable to the effect sizes obtained from the binary predictors (see Gelman, 2008). The bystander's social relation was measured with a binary variable, distinguishing bystanders who have a social relationship to an individual involved in the conflict from bystanders who do not know any of the conflict parties.

\subsection{3 | Control variables}

To control for omitted-variable bias and based on findings of prior studies, we included five control variables. The bystander's gender was coded as male or female. This variable was included because of evidence showing that men tend to act more "heroically and chivalrously" in their helping behavior than women (Eagly, 2009; Taylor et al., 2000). Nighttime drinking settings were defined as situations occurring in proximity to a bar/nightclub or during the weekend nights. This control variable was included as evidence shows that bystander involvement is a pervasive aspect of these settings (Levine et al., 2012; Parks, Osgood, Felson, Wells, \& Graham, 2013).

Further, given that most of our incidents occur in drinking settings, it is plausible that the intervention likelihood is shaped by whether the bystander is performing an occupational role, for 
example, as a bar staff or bouncer (Hobbs, 2003; Sampson, Eck, \& Dunham, 2010). The occupational role of bystanders was captured with a binary variable, distinguishing bystanders who were at work from those who were not. Because physical proximity between individuals may facilitate helping behavior (Fujisawa, Kutsukake, \& Hasegawa, 2006), we included a measurement of spatial proximity that distinguished whether the bystander was within a $2-m$ radius from where the conflict initiated.

Finally, as levels of crowding may be associated with antisocial outcomes at public venues (Macintyre \& Homel, 1997), we included people density as a control, distinguishing high density and low density situations. Density was assessed by whether it was possible to walk in a straight line across the setting without bumping into others present (low density) or not (high density).

\section{3 | RESULTS}

Figure 1 graphically shows the odds ratio estimates and associated confidence intervals of two multilevel binomial logistic regression models comparing bystander intervention with nonintervention. Full details of both models are presented in Table A3 in the Appendix. Both the key variables and control variables are listed on the vertical axis, while the effect sizes (odds ratios) are on the horizontal axis. The estimated odds ratios of the models are printed as dots and diamonds, respectively. The $95 \%$ percent confidence intervals are presented as horizontal lines around the estimates. The vertical line indicates an odds ratio of 1 , reflecting the absence of a statistical association.

The first model (estimates indicated in black with dots) includes only the two key variables, that is social relation and number of bystanders present. Contrary to the predicted reversed bystander effect, but in line with the classical bystander effect, we found that the number of bystanders is negatively associated with the likelihood of intervention. The effect size of this standardized variable (OR = 0.28) is medium-large, as evaluated with Rosenthal's (1996) odds ratio effects size categories. Confirming our expectation, having a social relationship tie to a conflict party is positively associated with intervention. Compared to a stranger, the odds of intervening are more than 20 times larger for a bystander with a social relation to a conflict party. Even if assessed conservatively from the lower band of the confidence interval $(95 \% \mathrm{Cl}=[9.98,42.17])$, the estimated odds ratio is very large.

In the second model (estimates shown in gray with diamonds) the five control variables are included to account for confounding relations with the key variables. Confounding is almost negligible, as the estimates of the two key variables are very similar to those in the first model ( 0.24 and 18.17 , respectively). With respect to the control variables, only the bystander's gender is significantly related to intervention, with men's odds of intervention being 3.6 times larger than that of women.

Finally, a test of the effect size difference between the two key variables is statistically significant in both the first model $\left(\chi^{2}(a)=85.52, p<.001\right)$ and in the second model including control variables $\left(\chi^{2}(a)=45.99, p<.001\right)$. This confirms the third hypothesis, which states that the social relation predictor is more strongly associated with intervention than the number of bystanders predictor.

To further explore whether the associations of intervention with bystander numbers and social relations generalize across deescalatory and escalatory intervention types, we decomposed the intervening bystanders into three groups: those who displayed only de-escalatory interventions, those who displayed only escalatory interventions, and those who displayed both de-escalatory and escalatory interventions (the mixed group). We estimated two multilevel multinomial logistic regression models to distinguish

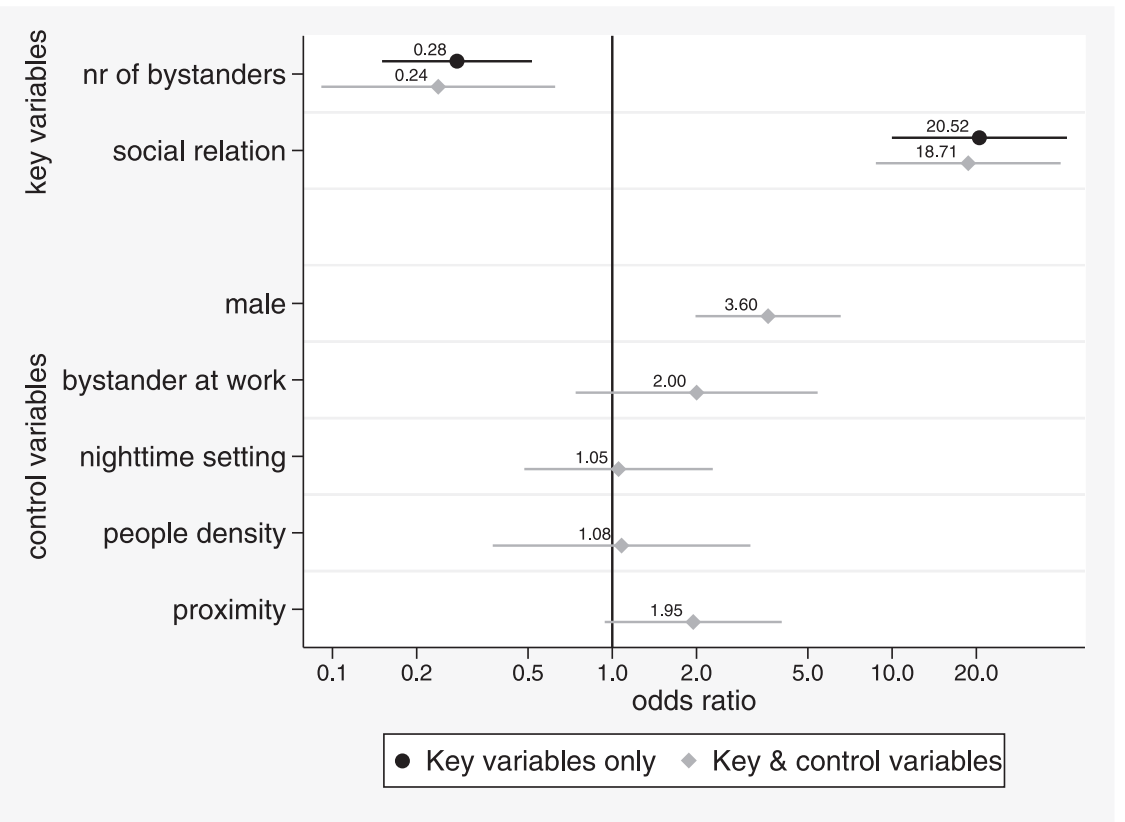

FIGURE 1 Multilevel binomial logistic regression estimates of bystander intervention. Complete results reported in Table A3 (Appendix) 
FIGURE 2 Multilevel multinomial logistic regression estimates of effects of key and control variables on decomposed bystander intervention. No intervention vs. de-escalatory, escalatory, and mixed interventions. Complete results reported in Table A4 (Appendix)

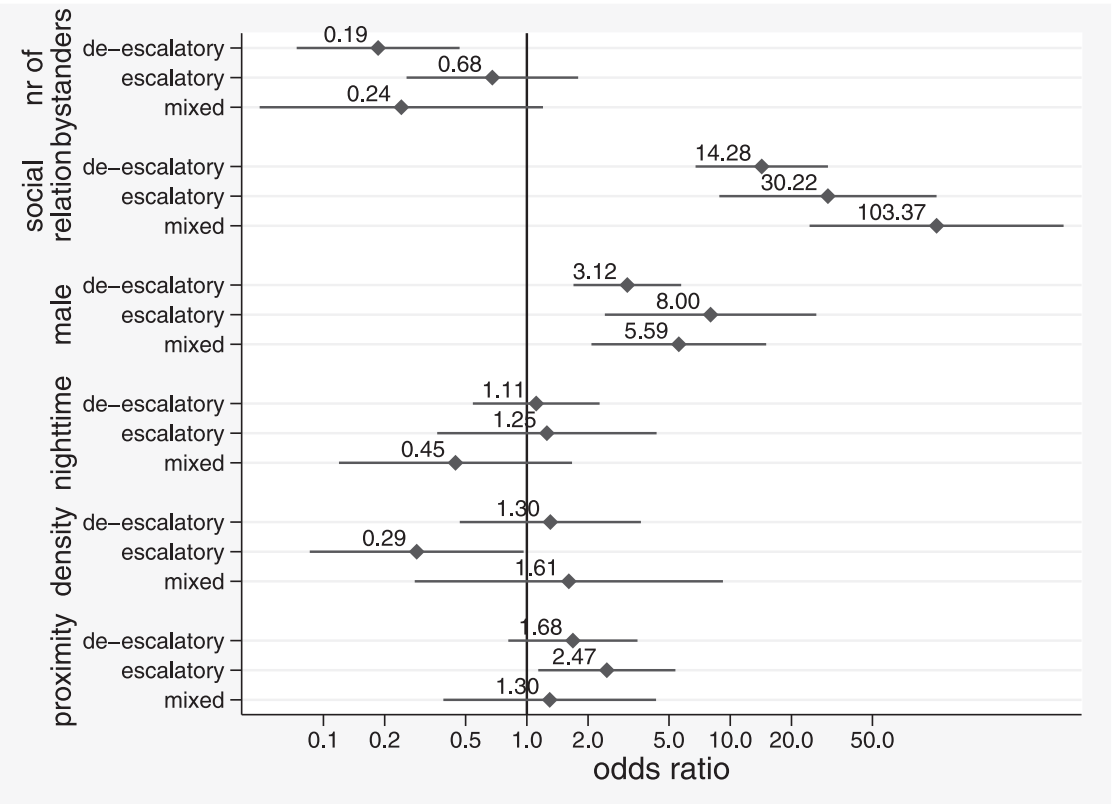

effects of the key and control variables across these three groups and the nonintervention reference category. Details of both models are presented in Table A4 in the Appendix. To limit the amount of information displayed, Figure 2 includes only the results of the model that includes both the key variables and the controls. Further, the variable that measured whether the bystander was acting in a professional role ("bystander at work") is excluded because it completely separates the escalatory intervention from nonintervention (i.e., no bystanders at work intervened in an escalatory manner), a phenomenon that renders it impossible to estimate the effect of the predictor in a logistic model.

From Figure 2 it can be seen that increasing numbers of bystanders are statistically associated with lower odds of a deescalatory intervention, while escalatory, and mixed intervention outcomes are not statistically related to the outcome. Additional tests demonstrate that the effect size difference between deescalatory intervention (0.19) and escalatory intervention (0.68) is significant $\left(\chi^{2}(a)=11.63, p<.01\right)$ but not the differences involving mixed intervention (for full statistics, see the Supporting Information Material at osf.io/r25wu). Next, social relations have a positive and statistically significant effect on the odds of all three intervention types. The difference between the estimates of the de-escalatory and the mixed intervention types is significant $\left(\chi^{2}(a)=8.17, p<.01\right)$ but not the differences involving escalatory intervention. Similar to the confirmatory analysis, gender is the only control variable significantly related to intervention. Men are more likely than women to display de-escalatory, escalatory, and mixed interventions. These effects sizes do not significantly differ between the three intervention types.

We conducted a number of sensitivity tests to assess the robustness of our findings against alternative reasonable data and model specifications. These include an alternative scaling method for our sampling weights, and a curvilinear effect of number of bystanders. In Figures 1 and 2 and the corresponding Tables A3 and A4 in Appendix A, we used scaling method A as described by Carle (2009). Following Carle's recommendation, we also used scaling method B to verify that our findings did not depend on the scaling method selected. This proved to be the case, given that all estimates barely differed across the scaling methods. These results are available in the online Supporting Information Material at osf.io/ r25wu.

Finally, given prior suggestions of a negative curvilinear association between number of bystanders and intervention (Latané, 1981), we estimated the four models shown in Tables A3 and A4 again, but with an added squared number of bystanders term. In support of this suggestion, the results demonstrate that for undifferentiated intervention and for de-escalatory intervention, the negative effect of each additional bystander becomes significantly weaker (less negative) as the number of bystanders increases. For example, going from two to three bystanders reduces the likelihood of intervention more than going from 12 to 13 bystanders. These results are also available in the online Supporting Information Material.

\section{4 | DISCUSSION}

Do people intervene into the danger of others at personal risk to themselves? The social sciences have a long tradition of stressing that third-party individuals are indifferent to the plight of others (Cohen, 2001; Manning et al., 2007; Milgram, 1970). A particularly influential account is offered by the bystander research field, which stipulates that people rarely intervene to help, because of the collective apathy generated by being together with others. In the present study, relying on naturally occurring data, we contrasted the number of bystanders present against an alternative explanation of bystander involvement that puts social relations between bystanders and conflict participants front stage. Our confirmatory analysis provided 
no evidence for the reversed bystander effect (Hypothesis 1). Rather, we found that additional bystanders make individual intervention less likely, as expected under the classical bystander effect hypothesis. Further, we found compelling evidence that the bystanders' social relations with conflict participants are associated with bystander intervention (Hypothesis 2), and that the effect size is larger in magnitude than that of the number of bystanders predictor (Hypothesis 3).

Further, our subsequent exploratory analysis of decomposed bystander intervention suggests that the negative effect of bystander numbers mainly applies to de-escalatory interventions, while social relations with conflict participants are highly predictive of all intervention types-whether de-escalatory, escalatory, or mixed. Finally, the sensitivity analysis indicates that the negative effect of the number of bystanders on de-escalatory intervention may diminish with increasing numbers of bystanders (i.e., a decreasing marginal effect), as suggested in earlier bystander research (Latané, 1981).

The bystander research field has for decades focused on people presence as the chief predictor of intervention behavior-initially as an explanation of nonintervention (Latané \& Darley, 1970), and more recently, in dangerous contexts, as a facilitator of intervention (Fischer et al., 2011). Here, with the largest data set of video captured real-life dangerous conflicts, we do not find evidence of a reversed bystander effect, but instead, a classical bystander effect. This is unexpected, given the recent paradigmatic shift toward an emergent consensus that additional bystanders offer physical support making intervention more likely, in particular in situations where nonintervention is dangerous for victims and intervention may be dangerous for interveners (Fischer \& Greitemeyer, 2013; Fischer et al., 2011; Levine et al., 2011).

The reported negative association between bystander numbers and intervention may be received as evidence that bystanders become increasingly apathetic toward the needs of others when situated in more populated contexts (Latané \& Darley, 1970). However, we also consider an alternative interpretation, not of collective apathy, but of helping saturation. Unlike the scarcely populated bystander experimental settings, public spaces often contain numerous individuals (with the current study finding an average of 18 bystanders per context), thus offering far more potential help-givers than required to manage a typical conflict. This relatively fixed upper bound of required help-givers has been shown to saturate at around three de-escalatory bystanders (Levine et al., 2011). As such, additional bystanders beyond this point may be surplus to requirements and thus unlikely to intervene (see also Bloch, Liebst, Poder, Christensen, \& Heinskou, 2018). The helping saturation hypothesis is empirically testable with CCTV footage because complete sequences of behavior of all participants are recorded second-by-second. By time stamping each recorded behavior, future investigations could statistically model the actions of bystanders as conditional on the previous behavior of other bystanders, and thus test the helping saturation hypothesis. ${ }^{3}$

The very strong association between social relations and intervention adds to the accumulating body of evidence showing that group membership strongly predicts bystander helping (Levine, Cassidy, \& Jentzsch, 2010; Lindegaard et al., 2017; Phillips \& Cooney, 2005; Slater et al., 2013). Beyond peacekeeping, social relations may also induce escalatory aggressive interventions. Here, the intervener acts not as a mediator but as a partisan who fights on behalf of friends or group members (Black, 1993; Phillips \& Cooney, 2005; Swann et al., 2010). Given the accumulating evidence supporting social relation as a key predictor of intervention behavior, it is unfortunate that helping research, and the social sciences more broadly, continue to emphasize the "power of situation," at the expense of exploring further the role of social relations (Lefevor, Fowers, Ahn, Lang, \& Cohen, 2017; Smith, 2015; Swann \& Jetten, 2017). The current intervention study, which compares the effect of situational bystander presence to the effect of social relationships, finds the latter predictor many-fold larger in magnitude. As such, people presence matters; in part, as a count in number, but more so as a consideration of the social ties existing between those present.

In addition to these two main predictors, we also included a number of control variables. Male bystanders were found to have a higher likelihood of intervention than females (across all intervention subtypes and model specifications). This is in line with evidence suggesting that although women are generally more helpful than men, males tend to be more strength-intensive in their helping strategies (Becker \& Eagly, 2004; Eagly, 2009), and as such, better positioned to engage in physical street violence interventions. Furthermore, occupational role (e.g., as a bouncer) was found to be a perfect predictor of the escalatory outcome category, with zero cases of bystander-workers intervening in a purely escalatory manner (see Table S3 in the Supporting Information Material). This finding suggests that professional "place managers" are less prone to use excessive force than indicated in prior research (e.g., Roberts, 2009; Sampson et al., 2010).

In utilizing naturally occurring data, the current work contributes to the scholarly understanding of actual bystander behavior as situated in emergencies where intervention may be dangerous. This was rendered possible by the sampling of police-reported events, all of which contained actual physical assaults. The current sample satisfies the call for research assessing bystander behavior in emergencies where intervention entails danger for the intervening person (Fischer et al., 2006), which is difficult to simulate ethically in the lab.

The reliance on police-reported data also incurs several limitations. As police-reported data are skewed toward more severely violent conflicts (Lindegaard \& Bernasco, 2018; Tarling \& Morris, 2010), our data does not capture the more mundane emergencies and nonviolent confrontations, commonplace in public settings (Copes, Hochstetler, \& Forsyth, 2013; Philpot, Liebst, Møller, Lindegaard, \& Levine, 2019). Furthermore, although bystander intervention was predominately de-escalatory in our data, it is likely that the current sample under-represents the proportion of deescalatory acts, while over-representing the escalatory acts, in the intervention outcome. Specifically, while escalatory bystander interventions may exacerbate the conflict and make it of greater interest to the police, other conflicts successfully de-escalated by bystanders, 
before they could become severe, are likely to be absent from our sample (Levine et al., 2012; Philpot, Liebst, Møller et al., 2019). As such, one should be wary of generalizing the current findings to bystander intervention occurring outside of high-danger, policereported assaults (see Berk, 1983). Where possible, future research should prioritize random probability sampling of emergency incidents, violent, and mundane alike (Lindegaard \& Bernasco, 2018; Philpot, Liebst, Møller et al., 2019).

A limitation of video clips captured by surveillance cameras is that there is no guarantee that violent conflicts can be observed in their entirety. In particular, because usually the cameras are fixed in space they cannot completely cover violent events that start in one place (e.g., inside a bar or club, or around the corner) and continue in front of the camera, or that they start in front of the camera and move out of sight. As a result, when interpreting findings it should be acknowledged that sometimes individuals who are bystanders in the recorded footage could have been antagonists in a phase of the conflict that took place outside the view of the camera. Thus, we should emphasize that the roles of "bystander" and "antagonist" remain situationally defined. To address this issue, and other issues of incomplete coverage, we suggest that future researchers try to triangulate observational CCTV data with information from other sources, including personal accounts of the individuals who were present during the incidents and, if available, police records (Philpot, Liebst, Møller et al., 2019).

As a final limitation, the very large effect size of group relations may, in part, be inflated because the coders (subconsciously, against their instructions) inferred the bystanders' relationship ties from whether or not the bystander intervened. In the current study, however, coders had detailed police case files accompanying each video, which were consulted to settle ambiguous video-based assessments of group membership. It is important to note that there were few discrepancies during this qualitative validation. Adding to this, the reported association between group relations and intervention is what one may expect, given that all prior studies (to our best knowledge) testing this association report a positive effect, typically of substantial magnitude. However, future bystander research should, ideally, consider conducting formal interrater validity tests (in addition to standard interrater reliability tests) in which videobased assessments are compared against ratings where group membership is definitively known (see Afifi \& Johnson, 2005).

Cialdini (1980) describes a "full cycle" psychology, by which experimentation should be prompted by the naturalistic observation of social phenomena (e.g., the murder of Kitty Genovese), and, in turn, validated through systematic real-world observation. The bystander research field, still largely contained in experimental work, is yet to fully confirm the ecological validity of its setup and findings. A case in point is that bystander studies typically compare rates of intervention when the bystander is alone versus when in the presence of a few others. The prevalence of numerous bystanders in public spaces suggests, however, that solitary conditions-similar to the simulation of nondangerous emergencies in the presence of strangers only-are over-studied artifacts of the laboratory. With real-life video data, we gain a greater understanding of how bystanders actually behave when together in numbers. This allows a reconsideration of whether nonintervention by individuals in populated settings reflects bystander apathy, or alternatively, bystander surplus. In taking such steps, the field may satisfy the final turn in Cialdini's (1980) cycle, and in doing so, recalibrate the "external invalidity" (Mook, 1983) of the experimental bystander paradigm toward a higher ecological validity.

Third-party conflict intervention is a probable human universal. Our work shows that this needs to be understood together with another universal, noted by Brown (1991): in-group favoritism. This bias toward one's own may promote de-escalatory helping toward familiar individuals, as shown in the current study. However, the boundaries of "us" and "them" may also be an obstacle for the provision of assistance to strangers (Bloom, 2017), and may promote pro-group partisan fighting on behalf of those known (Swann et al., 2010). We suggest that research gravitate away from chiefly using bystander counts to explain nonintervention. Rather, in our view, both the event and the non-event of bystander involvement, as well as its helpful and harmful consequences, calls for an appreciation of the group processes existing between those present.

\section{ACKNOWLEDGMENTS}

This study was supported by the Danish Council for Independent Research (DFF-6109-00210) and the Velux Foundation. The funders had no role in the design of the study, data collection and analysis, decision to publish, or preparation of the manuscript. We additionally thank Camilla Bank Friis and Anne Laura Engmann Juul for their contributions to the coding of CCTV footage.

\section{ENDNOTES}

${ }^{1}$ The study was approved by the Danish Data Protection Agency (reference 2015-57-0125-0026).

${ }^{2}$ Note that part of this video material is analyzed for another study purpose in Liebst et al. (2018).

${ }^{3}$ We owe this observation to an anonymous reviewer of this journal.

\section{ORCID}

Lasse Suonperä Liebst (ID http://orcid.org/0000-0003-1062-2447 Richard Philpot (D) http://orcid.org/0000-0002-0359-2123 Wim Bernasco (D) http://orcid.org/0000-0002-3385-0883 Kasper Lykke Dausel (D) http://orcid.org/0000-0001-5279-9000 Peter Ejbye-Ernst (D) http://orcid.org/0000-0003-4598-7235 Mathias Holst Nicolaisen (iD) http://orcid.org/0000-0002-0283-8144 Marie Rosenkrantz Lindegaard (D) http://orcid.org/0000-0002-1630$774 \mathrm{X}$

\section{REFERENCES}

Afifi, W. A., \& Johnson, M. L. (2005). The nature and function of tie-signs. In V. L. Manusov (Ed.), The sourcebook of nonverbal measures: Going beyond words (pp. 189-198). Mahwah, NJ: Psychology Press. 
Axelrod, R., \& Hamilton, W. (1981). The evolution of cooperation. Science, 211, 1390-1396.

Banyard, V. L. (2015). Toward the next generation of bystander prevention of sexual and relationship violence: Action coils to engage communities. London: Springer.

Baumeister, R. F., Vohs, K. D., \& Funder, D. C. (2007). Psychology as the science of self-reports and finger movements: Whatever happened to actual behavior? Perspectives on Psychological Science, 2, 396-403. https://doi.org/10.1111/j.1745-6916.2007.00051.x

Becker, S. W., \& Eagly, A. H. (2004). The heroism of women and men. American Psychologist, 59, 163-178.

Berk, R. A. (1983). An introduction to sample selection bias in sociological data. American Sociological Review, 48, 386-398. https://doi.org/10. $2307 / 2095230$

Black, D. (1993). The social structure of right and wrong. San Diego, CA: Academic Press.

Bloch, C., Liebst, L. S., Poder, P., Christiansen, J. M., \& Heinskou, M. B. (2018). Caring collectives and other forms of bystander helping behavior in violent situations. Current Sociology, 66, 1049-1069. https://doi.org/10.1177/0011392118776365

Bloom, P. (2017). Empathy and its discontents. Trends in Cognitive Sciences, 21, 24-31. https://doi.org/10.1016/j.tics.2016.11.004

Boehm, C. (2000). Conflict and the evolution of social control. Journal of Consciousness Studies, 7, 79-101.

Brown, D. E. (1991). Human universals. New York, NY: McGraw-Hill.

Carle, A. C. (2009). Fitting multilevel models in complex survey data with design weights: Recommendations. BMC Medical Research Methodology, 9, 49. https://doi.org/10.1186/1471-2288-9-49

Cherry, F. (1995). The 'stubborn particulars' of social psychology: Essays on the research process. London: Routledge.

Cialdini, R. B. (1980). Full-cycle social psychology. Applied Social Psychology Annual, 1, 21-47.

Cohen, S. (2001). States of denial: Knowing about atrocities and suffering. Cambridge: Polity Press.

Copes, H., Hochstetler, A., \& Forsyth, C. J. (2013). Peaceful warriors: Codes for violence among adult male bar fighters. Criminology, 51, 761-794. https://doi.org/10.1111/1745-9125.12019

Cross, C. P., Copping, L. T., \& Campbell, A. (2011). Sex differences in impulsivity: A meta-analysis. Psychological Bulletin, 137, 97-130.

Dael, N., Mortillaro, M., \& Scherer, K. R. (2012). Emotion expression in body action and posture. Emotion, 12, 1085-1101. https://doi.org/10. 1037/a0025737

Darley, J. M., \& Latane, B. (1968). Bystander intervention in emergencies: Diffusion of responsibility. Journal of Personality and Social Psychology, 8, 377-383. https://doi.org/10.1037/h0025589

Eagly, A. H. (2009). The his and hers of prosocial behavior: An examination of the social psychology of gender. American Psychologist, 64, 644-658. https://doi.org/10.1037/0003-066X.64.8.644

Eibl-Eibesfeldt, I. (1989). Human ethology. New York, NY: Aldine de Gruyter.

Fischer, P., Krueger, J. I., Greitemeyer, T., Vogrincic, C., Kastenmüller, A., Frey, D., ... Kainbacher, M. (2011). The bystander-effect: A metaanalytic review on bystander intervention in dangerous and nondangerous emergencies. Psychological Bulletin, 137, 517-537. https:// doi.org/10.1080/00224545.2012.697931

Fischer, P., \& Greitemeyer, T. (2013). The positive bystander effect: Passive bystanders increase helping in situations with high expected negative consequences for the helper. The Journal of Social Psychology, 153, 1-5. https://doi.org/10.1080/00224545.2012.697931

Fischer, P., Greitemeyer, T., Pollozek, F., \& Frey, D. (2006). The unresponsive bystander: Are bystanders more responsive in dangerous emergencies? European Journal of Social Psychology, 36, 267-278. https://doi.org/10.1002/ejsp.297

Fry, D. P. (2000). Conflict management in cross-cultural perspective. In F. Aureli, F. B. M., \& de Waal (Eds.), Natural conflict resolution (pp. 334-351). Berkeley, CA: University of California Press.
Fujisawa, K. K., Kutsukake, N., \& Hasegawa, T. (2006). Peacemaking and consolation in Japanese preschoolers witnessing peer aggression. Journal of Comparative Psychology, 120, 48-57. https://doi.org/10. 1037/0735-7036.120.1.48

Gelman, A. (2008). Scaling regression inputs by dividing by two standard deviations. Statistics in Medicine, 27, 2865-2873. https://doi.org/10. 1002/sim.3107

Goffman, E. (1971). Relations in public, Microstudies of the public order. New York, NY: Basic Books.

Grimes, D. A., \& Schulz, K. F. (2005). Compared to what? Finding controls for case-control studies. The Lancet, 365, 1429-1433. https://doi.org/ 10.1016/S0140-6736(05)66379-9

Harari, H., Harari, O., \& White, R. V. (1985). The reaction to rape by American male bystanders. The Journal of Social Psychology, 125, 653-658. https://doi.org/10.1080/00224545.1985.9712039

Hobbs, D. (2003). Bouncers: Violence and governance in the night-time economy. Oxford: Oxford University Press.

Hox, J. J., Moerbeek, M., \& van de Schoot, R. (2017). Multilevel analysis: Techniques and applications. London: Routledge.

Jones, L. K., Jennings, B. M., Goelz, R. M., Haythorn, K. W., Zivot, J. B., \& de Waal, F. B. M. (2016). An ethogram to quantify operating room behavior. Annals of Behavioral Medicine, 50, 487-496. https://doi.org/ 10.1007/s12160-016-9773-0

Keogh, R. H., \& Cox, D. R. (2014). Case-control studies. Cambridge: Cambridge University Press.

Krippendorff, K. (2004). Reliability in content analysis. Human Communication Research, 30, 411-433. https://doi.org/10.1111/j.1468-2958. 2004.tb00738.x

Latané, B. (1981). The psychology of social impact. American Psychologist, 36, 343-356. https://doi.org/10.1037/0003-066X.36.4.343

Latané, B., \& Nida, S. (1981). Ten years of research on group size and helping. Psychological Bulletin, 89, 308-324. https://doi.org/10.1037/ 0033-2909.89.2.308

Latané, B., \& Darley, J. M. (1970). The unresponsive bystander: Why doesn't he help? New York, NY: Appleton-Century-Crofts.

Lefevor, G. T., Fowers, B. J., Ahn, S., Lang, S. F., \& Cohen, L. M. (2017). To what degree do situational influences explain spontaneous helping behaviour? A meta-analysis. European Review of Social Psychology, 28, 227-256. https://doi.org/10.1080/10463283.2017.1367529

Levine, M., Cassidy, C., Brazier, G., \& Reicher, S. (2002). Self-categorization and bystander non-intervention: Two experimental studies. Journal of Applied Social Psychology, 32, 1452-1463. https://doi.org/ 10.1111/j.1559-1816.2002.tb01446.x

Levine, M., Lowe, R., Best, R., \& Heim, D. (2012). We police it ourselves': Group processes in the escalation and regulation of violence in the night-time economy: Night-time economy violence. European Journal of Social Psychology, 42, 924-932. https://doi.org/10.1002/ejsp.1905

Levine, M., Cassidy, C., \& Jentzsch, I. (2010). The implicit identity effect: Identity primes, group size, and helping. British Journal of Social Psychology, 49, 785-802. https://doi.org/10.1348/014466609X480426

Levine, M., \& Crowther, S. (2008). The responsive bystander: How social group membership and group size can encourage as well as inhibit bystander intervention. Journal of Personality and Social Psychology, 95, 1429-1439. https://doi.org/10.1037/a0012634

Levine, M., \& Manning, R. (2013). Social identity, group processes, and helping in emergencies. European Review of Social Psychology, 24, 225-251. https://doi.org/10.1080/10463283.2014.892318

Levine, M., Taylor, P. J., \& Best, R. (2011). Third parties, violence, and conflict resolution: The role of group size and collective action in the microregulation of violence. Psychological Science, 22, 406-412. https://doi.org/10.1177/0956797611398495

Lewallen, S., \& Courtright, P. (1998). Epidemiology in practice: Casecontrol studies. Community Eye Health, 11, 57-58.

Liebst, L. S., Heinskou, M. B., \& Ejbye-Ernst, P. (2018). On the actual risk of bystander intervention: A statistical study based on naturally 
occurring violent emergencies. Journal of Research in Crime and Delinquency, 55, 27-50. https://doi.org/10.1177/0022427817710776

Lindegaard, M. R., \& Bernasco, W. (2018). Lessons learned from crime caught on camera. Journal of Research in Crime and Delinquency, 55, 155-186. https://doi.org/10.1177/0022427817727830

Lindegaard, M. R., Liebst, L. S., Bernasco, W., Heinskou, M. B., Philpot, R., Levine, M., \& Verbeek, P. (2017). Consolation in the aftermath of robberies resembles post-aggression consolation in chimpanzees. PLOS One, 12):e0177725. https://doi.org/10.1371/journal.pone.0177725

Lohr, S. (2010). Sampling: Design and analysis. Boston, MA: Brooks/Cole.

Macintyre, S., \& Homel, R. (1997). Danger on the dance floor: A study of interior design, crowding and aggression in nightclubs. In R. Homel (Ed.), Policing for prevention: Reducing crime, public intoxication and injury (pp. 91-113). Monsey, NY: Criminal Justice Press.

Manning, R., Levine, M., \& Collins, A. (2007). The Kitty Genovese murder and the social psychology of helping: The parable of the 38 witnesses. American Psychologist, 62, 555-562. https://doi.org/10.1037/0003066X.62.6.555

McNeish, D. M., \& Stapleton, L. M. (2016). The effect of small sample size on two-level model estimates: A review and illustration. Educational Psychology Review, 28, 295-314. https://doi.org/10.1007/s10648014-9287-x

Milgram, S. (1970). The experience of living in cities. Science, 167, 1461-1468.

Mook, D. G. (1983). In defense of external invalidity. American Psychologist, 38, 379-387. https://doi.org/10.1037/0003-066X.38.4. 379

Mortensen, C. R., \& Cialdini, R. B. (2010). Full-cycle social psychology for theory and application. Social and Personality Psychology Compass, 4, 53-63. https://doi.org/10.1111/j.1751-9004.2009.00239.x

Murphy, N. A. (2016). What we know and the future of interpersonal accuracy research. In J. A. Hall, M. S. Mast, \& T. V. West (Eds.), The social psychology of perceiving others accurately (pp. 404-424). Cambridge: Cambridge University Press.

Nassauer, A., \& Legewie, N. (2012). Erratum for PMID 21180585. Sociological Methods \& Research, 5, 371. https://doi.org/10.1177/ 0049124118769093

Osswald, S., Greitemeyer, T., Fischer, P., \& Frey, D. (2010). What is moral courage? Definition, explication, and classification of a complex construct. In C. Pury, \& S. Lopez (Eds.), The psychology of courage: Modern research on an ancient virtue (pp. 149-164). Washington, DC: APA.

Parks, M. J., Osgood, D. W., Felson, R. B., Wells, S., \& Graham, K. (2013). Third party involvement in barroom conflicts. Aggressive Behavior, 39 , 257-268. https://doi.org/10.1002/ab.21475

Phillips, S., \& Cooney, M. (2005). Aiding peace, abetting violence: Third parties and the management of conflict. American Sociological Review, 70, 334-354. https://doi.org/10.1177/000312240507000207

Philpot, R. (2017). Beyond the dyad: The role of groups and third-parties in the trajectory of violence (Doctoral dissertation), University of Exeter, Exeter.

Philpot, R., Liebst, L. S., Levine, M., Bernasco, W., \& Lindegaard, M. R. (2019). Would I be helped? Cross-national CCTV footage shows that intervention is the norm in public conflicts. American Psychologist.

Philpot, R., Liebst, L. S., Møller, K. K., Lindegaard, M. R., \& Levine, M. (2019). Capturing violence in the night-time economy: A review of established and emerging methodologies. Aggression and Violent Behavior, 46, 56-65. https://doi.org/10.1016/j.avb.2019.02.004

Rabe-Hesketh, S., Skrondal, A., \& Pickles, A. (2005). Maximum likelihood estimation of limited and discrete dependent variable models with nested random effects. Journal of Econometrics, 128, 301-323. https:// doi.org/10.1016/j.jeconom.2004.08.017
Reynald, D. M. (2011). Factors associated with the guardianship of places: Assessing the relative importance of the spatio-physical and sociodemographic contexts in generating opportunities for capable guardianship. Journal of Research in Crime and Delinquency, 48, 110-142.

Roberts, J. C. (2009). Bouncers and barroom aggression: A review of the research. Aggression and Violent Behavior, 14, 59-68. https://doi.org/ 10.1016/j.avb.2008.10.002

Rosenthal, J. A. (1996). Qualitative descriptors of strength of association and effect size. Journal of Social Service Research, 21, 37-59. https:// doi.org/10.1300/J079v21n04_02

Sampson, R., Eck, J. E., \& Dunham, J. (2010). Super controllers and crime prevention: A routine activity explanation of crime prevention success and failure. Security Journal, 23, 37-51. https://doi.org/10.1057/sj. 2009.17

Slater, M., Rovira, A., Southern, R., Swapp, D., Zhang, J. J., Campbell, C., \& Levine, M. (2013). Bystander responses to a violent incident in an immersive virtual environment. PLOS One, 8):e52766. https://doi.org/ 10.1371/journal.pone.0052766

Smith, C. (2015). To flourish or destruct: a personalist theory of human goods, motivations, failure, and evil. University of Chicago Press.

Steegen, S., Tuerlinckx, F., Gelman, A., \& Vanpaemel, W. (2016). Increasing transparency through a multiverse analysis. Perspectives on Psychological Science, 11, 702-712. https://doi.org/10. 1177/1745691616658637

Swann, W. B., Gómez, Á., Huici, C., Morales, J. F., \& Hixon, J. G. (2010). Identity fusion and self-sacrifice: Arousal as a catalyst of pro-group fighting, dying, and helping behavior. Journal of Personality and Social Psychology, 99, 824-841. https://doi.org/10.1037/a0020014

Swann, W. B., \& Jetten, J. (2017). Restoring agency to the human actor. Perspectives on Psychological Science, 12, 382-399. https://doi.org/10. 1177/1745691616679464

Tarling, R., \& Morris, K. (2010). Reporting crime to the police. The British Journal of Criminology, 50, 474-490. https://doi.org/10.1093/bjc/ azq011

Taylor, S. E., Klein, L. C., Lewis, B. P., Gruenewald, T. L., Gurung, R. A. R., \& Updegraff, J. A. (2000). Biobehavioral responses to stress in females: Tend-and-befriend, not fight-or-flight. Psychological Review, 107, 411-429. https://doi.org/10.1037//0033-295X.107.3.411

Vázquez, A., Gómez, Á., Ordoñana, J. R., Swann, W. B., \& Whitehouse, H. (2017). Sharing genes fosters identity fusion and altruism. Self and Identity, 16, 684-702. https://doi.org/10.1080/15298868.2017. 1296887

de Waal, F. B. M. (2015). Prosocial primates. In D. A. Schroeder, \& W. G. Graziano (Eds.), The Oxford handbook of prosocial behavior (pp. 61-85). Oxford: Oxford University Press.

de Waal, F. B. M., \& Preston, S. D. (2017). Mammalian empathy: Behavioural manifestations and neural basis. Nature Reviews Neuroscience, 18, 498-509. https://doi.org/10.1038/nrn.2017.72

Weina ge, Ge, Collins, R. T., \& Ruback, R. B. (2012). Vision-based analysis of small groups in pedestrian crowds. IEEE Transactions on Pattern Analysis and Machine Intelligence, 34, 1003-1016. https://doi.org/10. 1109/TPAMI.2011.176

How to cite this article: Liebst LS, Philpot R, Bernasco W, et al. Social relations and presence of others predict bystander intervention: Evidence from violent incidents captured on CCTV. Aggressive Behavior. 2019;45:598-609. https://doi.org/10.1002/ab.21853 


\section{APPENDIX A}

TABLE A1 Summary of bystander intervention codes used to construct the outcome variables

\begin{tabular}{|c|c|c|}
\hline Behavior & Qualitative definition & Type \\
\hline Open hand gestures & The bystander displays a calming hand movement with open hands. & De-escalatory \\
\hline Nonforceful touching & The bystander touches a person in a nonforceful manner. & De-escalatory \\
\hline Blocking contact between conflict parties & The bystander blocks a person from reaching a conflict party (i.e., acting as a barrier). & De-escalatory \\
\hline Holding a person back & $\begin{array}{l}\text { The bystander holds a person back from moving further toward the conflict or conflict } \\
\text { partner. }\end{array}$ & De-escalatory \\
\hline Hauling a person off & $\begin{array}{l}\text { The bystander holds a person and pulls/carries that individual away from the conflict } \\
\text { or conflict partner. }\end{array}$ & De-escalatory \\
\hline Pushing & $\begin{array}{l}\text { The bystander pushes a person away from the conflict or conflict partner in a } \\
\text { nonaggressive manner. }\end{array}$ & De-escalatory \\
\hline Pointing and threatening gestures & $\begin{array}{l}\text { The bystander displays an aggressive hand movement, typically pointing at someone in } \\
\text { a threating manner. }\end{array}$ & Escalatory \\
\hline Throw a person & $\begin{array}{l}\text { The bystander firmly grips a person and then throws that person in an aggressive } \\
\text { manner. }\end{array}$ & Escalatory \\
\hline Shoving & The bystander shoves a person in a forceful and aggressive manner. & Escalatory \\
\hline Hit & The bystander hits a person with either an open or closed hand. & Escalatory \\
\hline Several hits & The bystander hits several times with either an open or closed hand. & Escalatory \\
\hline Kick & The bystander kicks a person. & Escalatory \\
\hline Several Kicks & The bystander kicks a person several times. & Escalatory \\
\hline Kick to the head & The bystander kicks a person to the head or stomps on a person's head. & Escalatory \\
\hline Violence against a person on the ground & The bystander physically attacks a person on the ground. & Escalatory \\
\hline Weapon use & $\begin{array}{l}\text { The bystander physically attacks a person with an object (e.g., billiard ball, bottle, } \\
\text { knife). }\end{array}$ & Escalatory \\
\hline
\end{tabular}

Note: The above codes were used to construct the binary intervention outcome (i.e., any intervention or none), as well as the bystander intervention outcome decomposed into four outcomes (i.e., de-escalatory, escalatory, mixed, and none). The Krippendorff's $\alpha$ 's of the de-escalatory and escalatory intervention codes are .92 and .82, respectively. A mixed outcome is coded for bystanders displaying both escalatory and de-escalatory interventions.

TABLE A2 Summary of independent variable definitions and related Krippendorff's $\alpha$ 's

\begin{tabular}{|c|c|c|}
\hline Variable & Description & Krippendorff's $\alpha$ \\
\hline Number of bystanders & The number of bystanders present in the situation at the point when the conflict initiates. & 0.85 \\
\hline Social relation & $\begin{array}{l}\text { The bystander knows at least one person who is physically involved in the conflict. We apply a } \\
\text { minimal definition of relationship ties, which include everything from ties established the same } \\
\text { day to family ties. }\end{array}$ & 1.0 \\
\hline Male & Gender based on the bystander's visual appearance. & 1.0 \\
\hline Bystander at work & $\begin{array}{l}\text { The bystander is performing an occupational role (e.g., as a bouncer or bar staff). Excludes } \\
\text { emergency services (e.g., medics or police officers). }\end{array}$ & 1.0 \\
\hline Nighttime drinking setting & $\begin{array}{l}\text { The incident took place } 10 \text { p.m.-7 a.m. during the weekend, or if inside/in front of a drinking } \\
\text { establishment. }\end{array}$ & 1.00 \\
\hline High density & $\begin{array}{l}\text { The density of everyone present in the situation at the point when the conflict initiates. High } \\
\text { density is assessed from whether it is possible to walk across the setting (i.e., dance floor and } \\
\text { street) in a straight line, without bumping into someone present. }\end{array}$ & 0.83 \\
\hline
\end{tabular}


TABLE A3 Multilevel binomial logistic regression estimates of bystander intervention

\begin{tabular}{|c|c|c|c|c|c|c|}
\hline & \multicolumn{3}{|c|}{ Key variables only } & \multicolumn{3}{|c|}{ Key and control variables } \\
\hline & OR & $95 \% \mathrm{Cl}$ & $p$ & OR & $95 \% \mathrm{Cl}$ & $p$ \\
\hline Number of bystanders & $0.28^{* * *}$ & $0.15-0.52$ & .00 & $0.24^{* *}$ & $0.09-0.62$ & .00 \\
\hline Male & & & & $3.60^{* * *}$ & $1.98-6.55$ & .00 \\
\hline Bystander at work & & & & 2.00 & $0.74-5.42$ & .17 \\
\hline High density & & & & 1.08 & $0.37-3.12$ & .89 \\
\hline Spatial proximity & & & & 1.95 & $0.94-4.03$ & .07 \\
\hline N1 (individuals) & 751 & & & 741 & & \\
\hline N2 (incidents) & 81 & & & 80 & & \\
\hline
\end{tabular}

Abbreviations: $\mathrm{Cl}$, confidence interval; OR, odds ratio; ${ }^{* *} p<.001{ }^{* *} p<.01{ }^{*} p<.05$.

TABLE A4 Multilevel multinomial logistic regression estimates of decomposed bystander intervention

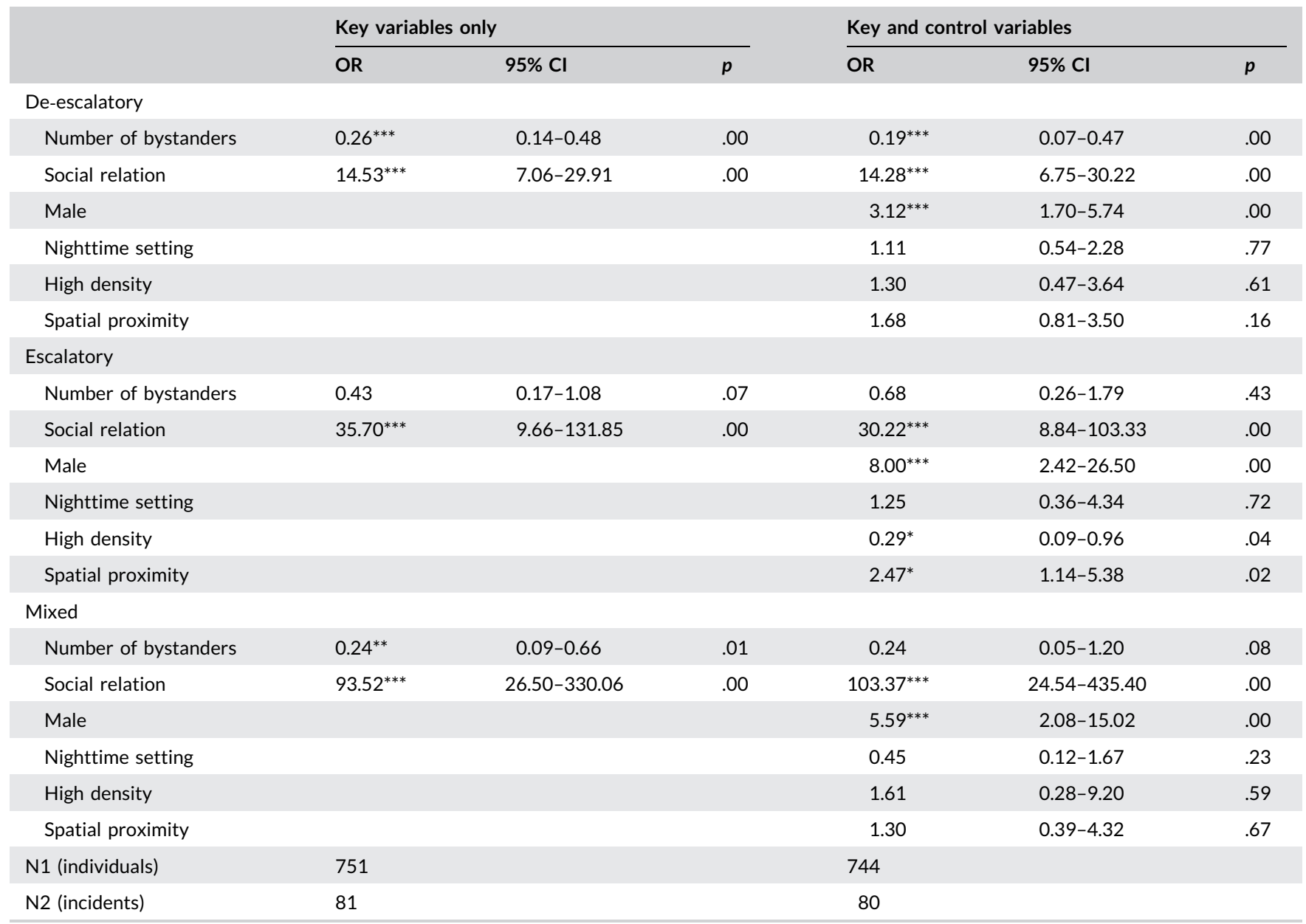

Abbreviations: $\mathrm{Cl}$, confidence interval; OR, odds ratio. ${ }^{* * *} p<.001,{ }^{* *} p<.01,{ }^{*} p<.05$. 